\title{
Regulation of T-cell death-associated gene 51 (TDAG51) expression in human T-cells
}

\author{
H-H Oberg ${ }^{1}$, B Sipos ${ }^{2}$, H Kalthoff ${ }^{3}$, O Janssen ${ }^{1}$ and D Kabelitz ${ }^{\star 1}$ \\ 1 Institute of Immunology, University Hospital Schleswig-Holstein Campus Kiel, \\ Kiel, Germany \\ 2 Department of Pathology, University Hospital Schleswig-Holstein Campus \\ Kiel, Kiel, Germany \\ ${ }^{3}$ Department of Molecular Oncology, University Hospital Schleswig-Holstein \\ Campus Kiel, Kiel, Germany \\ * Corresponding author: D Kabelitz, Institute of Immunology, UK S-H Campus \\ Kiel Michaelisstrasse 5 Kiel D-24105, Germany. Tel: + 49-431-5973340; \\ fax: + 49-431-5973335; E-mail: kabelitz@immunologie.uni-kiel.de
}

Received 23.9.03; revised 18.12.03; accepted 23.12.03; published online 27.02.04 Edited by Dr B Osborne

\section{Abstract \\ T-cell death-associated gene 51 (TDAG51) has been described to regulate T-cell receptor/CD3-dependent induction of CD95/ Fas and subsequent activation-induced cell death (AICD) in a murine T-cell hybridoma. Using well-defined pharmacological inhibitors, we investigated the regulation of TDAG51 expres- sion in human T-cells and the correlation with cell death. TDAG51 was induced in resting T-cells, lymphoid cell lines and AICD-susceptible as well as AICD-resistant T-cell clones, and induction was inhibited by MAP-kinase inhibitors and PKC inhibitor Gö6983. No correlation between the effects of inhibitors on TDAG51 expression and cell death was observed. The constitutive TDAG51 expression in five pancreatic carcinoma cell lines was reduced by MAP-kinase inhibitors but not by Gö6983. Furthermore, the inducible overexpression of TDAG51 in TetOn Jurkat cells did not modulate cellular proliferation, phorbolester/ionomycin-in- duced growth arrest, or the expression of various cell surface molecules. Our results indicate that the expression of TDAG51 in human T-cells does not correlate with AICD. \\ Cell Death and Differentiation (2004) 11, 674-684. \\ doi:10.1038/sj.cdd. 4401407 \\ Published online 27 February 2004}

Keywords: apoptosis; Fas expression; T-cell receptor; T-lymphocytes

Abbreviations: AICD, activation-induced cell death; Doxy, doxycycline; FasL, Fas-ligand; MAP kinase, mitogen-activated protein kinase; $\mathrm{mAb}$, monoclonal antibody; PKC, protein kinase C; TCR, T-cell receptor; TDAG51, T-cell death-associated gene 51;

\section{Introduction}

Activated but not resting T-cells undergo activation-induced cell death (AICD) when the T-cell receptor (TCR) is triggered via crosslinking of cell surface $\mathrm{CD} 3$ or superantigens such as staphylococcal enterotoxins. ${ }^{1}$ AICD proceeds through the TCR-mediated upregulation of Fas-ligand (FasL, CD178) and Fas (CD95) expression and subsequent triggering of Fas/ FasL-dependent apoptosis. ${ }^{2-4}$ Despite the upregulation of CD95 following TCR stimulation of resting T-cells, these cells remain AICD-resistant for approximately 6 days, ${ }^{5}$ due to the extended presence of FLIP in the death-inducing signalling complex $^{6-9}$ and a block in the mitochondrial apoptosis pathway. ${ }^{10}$ While the molecular mechanisms of Fas/FasLtriggered apoptosis have been investigated extensively, ${ }^{11}$ it is less clear how CD95 is induced in T-cells follwing TCRmediated antigen recognition or CD3-crosslinking by antiCD3 monoclonal antibodies (mAb). In this regard, the T-cell death-associated gene 51 (TDAG51) has been isolated by its ability to rescue a murine $\mathrm{T}$-cell hybridoma from its resistance towards AICD after TCR ligation. ${ }^{12}$ In these cells, the induction of Fas expression was dependent on the presence of TDAG51, and TDAG51 mRNA was rapidly induced independently of de novo protein biosynthesis. Although these results suggested that TDAG51 is the critical link between AICD and the TCR-mediated upregulation of CD95, T-cells from gene-targeted TDAG51 ${ }^{-1-}$ mice did not suffer from major defects in TCR-mediated CD95 expression or execution of AICD, indicating that TDAG51 is not truly essential for CD95 induction. ${ }^{13}$ Rat and human homologues of TDAG51 have been isolated by differential mRNA display approaches. ${ }^{14,15}$ Microinjection of rat TDAG51 cDNA into a neuronal cell line increased CD95-independent cell death, while the microinjection of an anti-TDAG51 antibody prevented differentiation-induced apoptosis. ${ }^{14}$ Human TDAG51 was found to be constitutively expressed in benign melanocytic nevi and to be progressively reduced in primary and metastatic melanomas. ${ }^{15}$ Taken together, the available evidence suggests that TDAG51 is involved in the regulation of cell growth and cell death, but not necessarily through effects on CD95 expression.

Murine, rat and human TDAG51 share $90 \%$ identity on the amino-acid level. Their amino-acid sequence comprises a stretch of glutamines at the $\mathrm{N}$-terminus and a proline/histidinerich repeat, which is directly followed by a proline/glutaminerich repeat at the C-terminus. ${ }^{12,14,15}$ The human TDAG51 contains two start codons, potentially giving rise to two proteins of $60 \mathrm{kDa}$ (Met 1) and $40 \mathrm{kDa}$ (Met 142), of which only the $40 \mathrm{kDa}$ form seems to get expressed. ${ }^{15}$ Furthermore, the human gene contains a potential protein kinase $C$ (PKC) phosphorylation site at position Ser 293. A role of PKC in the regulation of TDAG51 expression was suggested by the observation that phorbolester PMA alone induced TDAG51 mRNA in a murine T-cell hybridoma. ${ }^{16}$

In the present study, we have investigated the regulation of TDAG51 expression in human T-cells and pancreatic tumor cells. In order to analyze the impact of TDAG51 expression on T-cell growth and surface antigen expression, we generated inducible Jurkat transfectants using the TetOn system. Our results indicate a role of mitogen-activated protein (MAP) 
kinases in the inducible and constitutive expression of TDAG51 in human T-cells and tumor cells, but no direct correlation between cell death, AICD, cellular proliferation and the expression of TDAG51 protein.

\section{Results}

\section{TDAG51 expression is not restricted to human T-cells}

TDAG51 mRNA is ubiquitously expressed in most murine tissues and cell lines. ${ }^{12}$ To investigate TDAG51 protein expression in human leukocyte subsets, we tested different Jurkat variants (the parental JE6.1 and the Fas-resistant JM319), EBV-transformed B-lymphoblastoid cell lines, Daudi Burkitt's lymphoma cells and U937 histiocytic lymphoma cells. In all cell lines analyzed, TDAG51 protein was detectable after stimulation with phorbolester PMA plus ionomycin (Figure 1a). At the level of mRNA, no constitutive expression was detectable in Jurkat JE6.1 cells (Figure 1c). For comparison, we analyzed different pancreatic tumor cell lines (Panc-1, CFPAC-1, Capan-1, BxPC-3, PancTu-1, Colo357, PT45P1). Interestingly, these epithelial tumor cells constitutively expressed TDAG51 protein (Figure 1b) and mRNA (Figure 1c). Stimulation with PMA plus ionomycin did not significantly modulate the constitutive TDAG51 protein expression (Figure 1b). These results prompted us to investigate the constitutive expression of TDAG51 in samples of human tumors. Strong in situ expression of TDAG51 protein was observed in a human pancreatic carcinoma (Figure 1d, large picture) and in 14 out of 23 additionally analyzed pancreas tumors. In contrast, no TDAG51 expression was observed in ductal epithelial cells of all five analyzed normal pancreatic tissue sections (Figure 1d, small picture).

\section{Time course kinetics of TDAG51 induction in resting human T-cells}

Time course experiments with freshly isolated T-cells indicated a rapid TDAG51 protein induction following stimulation with PMA/ionomycin. Protein expression was clearly discernible after $4 \mathrm{~h}$, and peaked after $24 \mathrm{~h}$ (Figure 2a), whereas only a faint band was observed 12 or $24 \mathrm{~h}$ after stimulation with immobilized anti-CD3 mAb alone (Figure 2a). Prolonged time course experiments over 6 days did not reveal an additional increase in protein expression (data not shown). In order to correlate TDAG51 protein induction with the expression of activation markers following $\mathrm{T}$-cell stimulation, we determined the surface expression of CD25, CD69, HLA-DR and CD95 by flow cytometry (Figure 2b). CD25 induction above basal levels started after $6-8 \mathrm{~h}$ and reached a maximum after $48-72 \mathrm{~h}$, with similar kinetics for PMA/ionomycin (Figure 2a, gray bars) and anti-CD3 (Figure 2a, black bars) stimulation. CD69 was rapidly induced by $\mathrm{PMA} /$ ionomycin with maximal expression after 4-6h, whereas delayed CD69 expression was induced by anti-CD3 stimulation. HLA-DR, a known 'late' activation marker of human T-cells, was not detectable before $72 \mathrm{~h}$ following stimulation. Induction of CD95 started $24 \mathrm{~h}$ after stimulation, and reached peak levels after $72 \mathrm{~h}$ stimulation with PMA/ionomycin or anti-CD3 $\mathrm{mAb}$. These results indicate

a

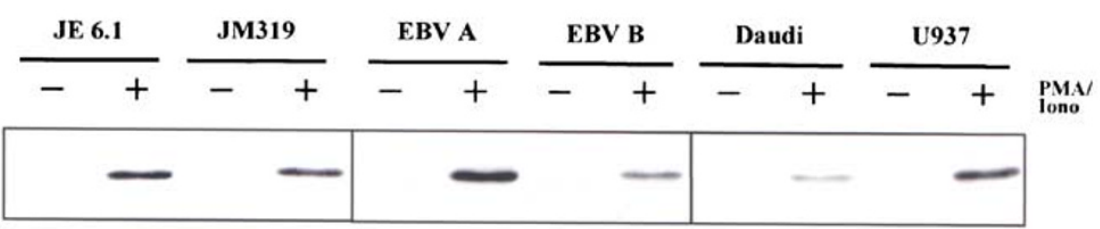

b

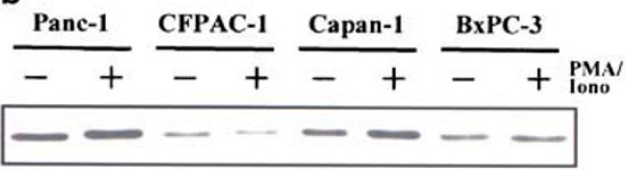

d

C
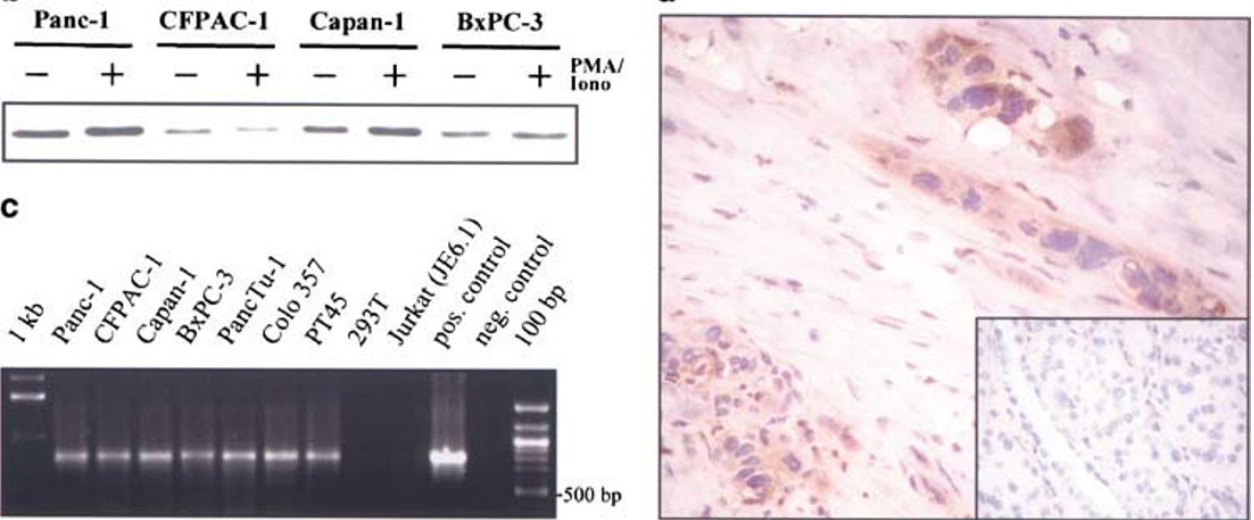

Figure 1 TDAG51 expression in lymphoid cells and tumor cells. Two Jurkat T-cell variants (parental JE6.1 and Fas-resistant JM319), two EBV-transformed B cell lines (EBV A, B), the Burkitt's lymphoma Daudi and the monocytic line U937 (a), as well as four representative pancreatic tumor cell lines (b), were cultured for $5 \mathrm{~h}$ without or with PMA and ionomycin. TDAG51 protein expression in total cell lysates was determined by Western blot analysis using the polyclonal anti-TDAG51 antibody L-19 (Santa Cruz). RT-PCR analysis of constitutive TDAG51 mRNA expression in different tumor cell lines, 293T cells and Jurkat (JE6.1) cells is shown in (c). A pcDNA3.1 plasmid containing the full-length sequence of human TDAG51 served as a positive control. Results of a representative out of five experiments are shown (c). Immunohistology of normal pancreatic tissue (small insert) and ductal pancreatic carcinoma tissue section (large picture) stained with anti-TDAG51 mAb PHLDA-1 (d) 


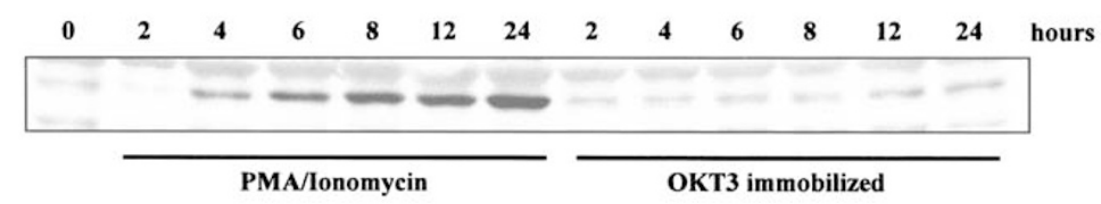

b
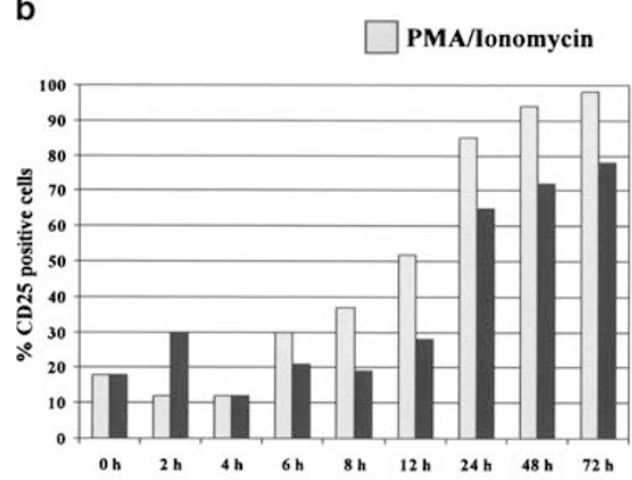

OKT3 immobilized
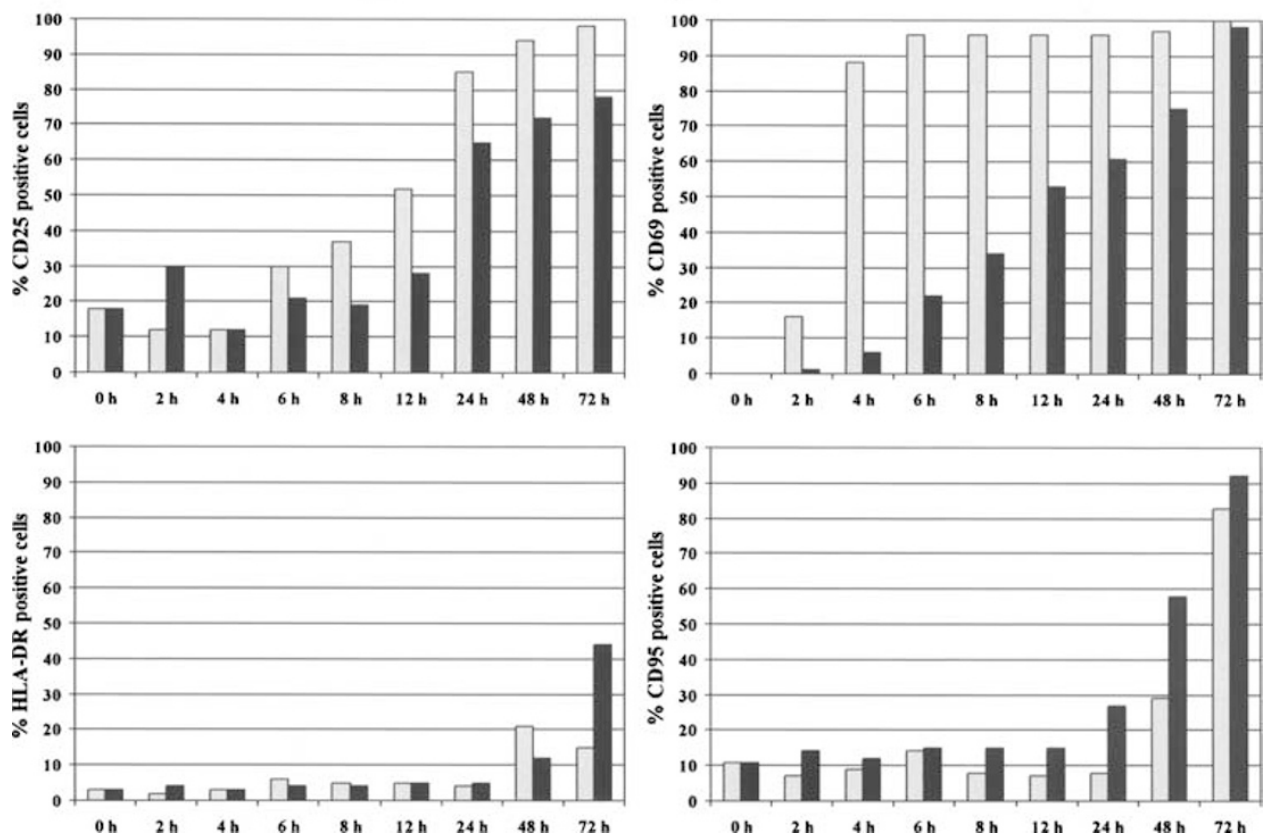

Figure 2 Time course kinetics of TDAG51 protein induction and activation marker expression in resting human T-cells. Freshly isolated T-cells were stimulated with PMA plus ionomycin or immobilized anti-CD3 mAb OKT3 for the indicated time periods (2-24 h). TDAG51 expression in total cell lysates was determined using the polyclonal anti-TDAG51 antibody L-19 (a). Cell surface expression of CD25, CD69, HLA-DR and CD95 was analyzed in parallel by flow cytometry after stimulation for 2-72 $\mathrm{h}$ with PMA/ionomycin (gray columns) or immobilized anti-CD3 mAb OKT3 (black columns) (b). Gates were set on lymphocytes, based on forward- and side-scatter properties, and the percentages of positive cells are indicated on the $Y$-axis. One out of three experiments is shown

a correlation between CD69 expression and TDAG51 protein induction in human T-cells in response to stimulation with PMA/ionomycin.

Next, we investigated the effect of well-characterized inhibitors of the MAP kinase and protein kinase C (PKC) pathways on the induction of CD95 and TDAG51 expression in freshly isolated T-cells. As shown in Figure 3a, the MAPkinase inhibitor U0126 suppressed the TDAG51 induction by anti-CD3/anti-CD28 mAb crosslinking, and PKC inhibitor Gö6981 inhibited TDAG51 induction by both anti-CD3/antiCD28 and PMA/ionomycin stimulation. Both inhibitors exerted similar inhibitory effects on the anti-CD3/anti-CD28-stimulated induction of CD95 on freshly isolated T-cells (Figure 3b), indicating that both TDAG51 and CD95 induction are regulated by MAP kinases and PKC.

\section{TDAG51 expression in T-cell clones is regulated by MAP kinases and PKC and does not correlate with cell death}

We have previously characterized AICD-sensitive and AICDresistant IL-2-dependent human T-cell clones which did not differ in their CD95 expression. ${ }^{17}$ As shown in Figure 4a, TDAG51 protein expression was readily induced in the AICDsensitive T-cell clone D798/18 but also in the AICD-resistant clone D566/4. Stimulation with PMA or PMA/ionomycin for $6 \mathrm{~h}$ induced a stronger protein expression than immobilized antiCD3 mAb, while crosslinking with anti-CD4 mAb did not induce TDAG51 expression (Figure 4a). We also tested different MAP-kinase inhibitors (U0126, PD98059, SB203580), which block downstream events of the Ras/Raf signaling pathway, the PKC inhibitor Gö6983, src-kinase inhibitor herbimycin A, PI3-kinase inhibitor wortmannin and FK506, which blocks calcium/calmodulin-dependent kinases, for their effects on the regulation of TDAG51 protein expression in these clones. In a representative experiment depicted in Figure $4 \mathrm{~b}-\mathrm{e}$, we compared the TDAG51 protein expression by Western blot with cell death, as analyzed by propidium iodide (PI) staining and flow cytometry. To quantify the reduction of the TDAG51 expression in the presence of inhibitors, we adjusted the protein bands to the $\beta$-actin expression by densitometric analysis and determined the reduction in TDAG51 protein expression in relation to the positive control (pos). The results of the quantitative analysis of the experiment shown in Figure $4 \mathrm{~b}-\mathrm{e}$ are presented in 
a

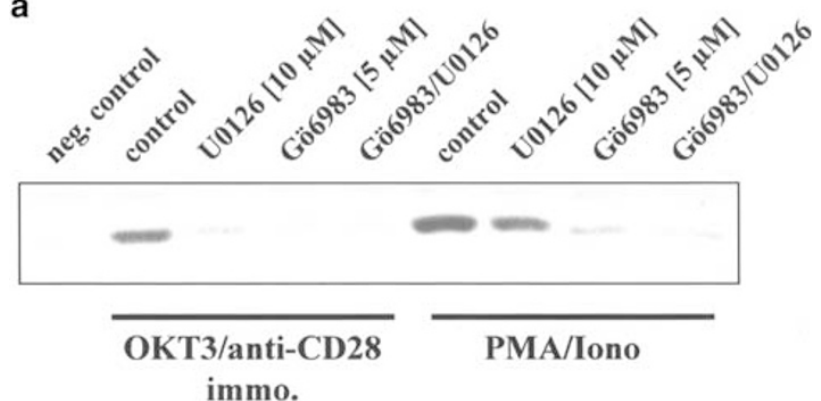

b
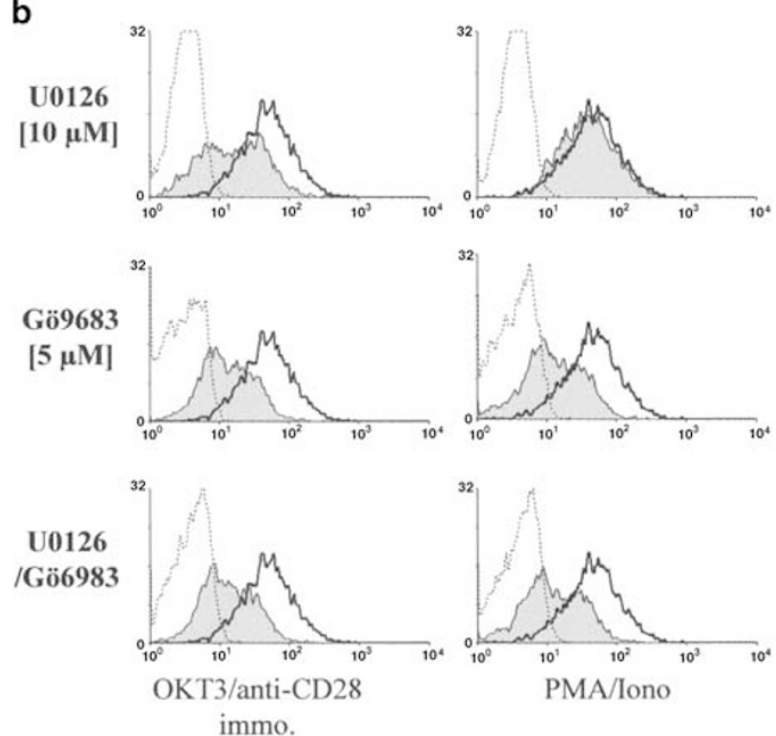

immo.

Figure 3 Inhibition of CD95 and TDAG51 expression in freshly isolated T-cells. Purified T-cells were cultured with immobilized anti-CD3 + anti-CD28 mAb or PMA/ionomycin in the absence or presence of ERK1/2 inhibitor U0126 $(10 \mu \mathrm{M})$ or PKC inhibitor Gö6983 (5 $\mu \mathrm{M})$. TDAG51 expression (a) and CD95 expression (b) were determined after $18 \mathrm{~h}$ by Western blot and flow cytometry, respectively. In (b), CD95 expression in the absence of inhibitor is shown as a solid line in the presence of inhibitor as a shaded histogram. Dotted line: isotype control

Table 1. When cells of the AICD-sensitive clone D798/18 and the AICD-resistant clone D596/6 were stimulated with PMA/ ionomycin (Figure 4b,c) or anti-CD3mAb (Figure 4d,e), TDAG51 protein expression was clearly reduced after preincubation with ERK1/2 inhibitor U0126 and PKC inhibitor Gö6983, whereas ERK1/2 inhibitor PD98059 and p38 inhibitor SB203580 caused only a weak reduction. Interestingly, the combination of Gö6983 with any of the MAP kinase inhibitors U0126, PD98059, or SB203580 strongly inhibited the induction of TDAG51 protein expression in response to PMA/ionomycin (Figure 4b, c) and anti-CD3 mAb (Figure 4d, e), resulting in TDAG51 expression levels comparable to those of untreated cells (neg). Herbimycin A, wortmannin and FK506 exerted variable effects, with little impact on the antiCD3-induced TDAG51 expression in D798/18 cells and a more pronounced inhibitory effect in D596/6 cells. Stimulation of $\mathrm{T}$-cell clones with PHA or superantigen SEA/E revealed comparable results (not shown). Cell death analysis (PIstaining) performed in parallel on the same cell samples did not show any correlation with TDAG51 expression (Figure $4 \mathrm{~b}-\mathrm{e}$ and Table 1). Thus, the combination of MAP-kinase inhibitors and Gö6983 drastically reduced the TDAG51 protein expression in response to PMA/ionomycin, but did not significantly modulate cell death in comparison to the positive control (cell death in the presence of PMA/ionomycin but absence of inhibitors; Figure 4b, c). Furthermore, CD3 crosslinking did not trigger cell death in AICD-resistant clone D596/6, yet induced a strong TDAG51 protein expression (Figure $4 \mathrm{e}$ ). The combination of MAP-kinase inhibitors and Gö6983 was also most efficient in preventing TDAG51 induction in response to superantigens and PHA (not shown). We also investigated the constitutive CD95 and inducible TDAG51 expression in PHA-blasts, which were cultured for 20 days in $\mathrm{CM}$ supplemented with rIL-2. While immobilized anti-CD3/anti-CD28 mAb and PMA induced TDAG51 expression (Figure 5a), they did not modulate the constitutive CD95 expression (Figure $5 \mathrm{~b}$ ) in these activated T-cells. Moreover, MAP kinase and PKC inhibitors did not inhibit the constitutive CD95 expression on activated T-cells under these conditions (not shown). Collectively, these results clearly indicate that cell death and CD95 expression do not correlate with TDAG51 protein expression in human T-cell clones. On the other hand, these results suggest that the Ras/Raf signalling pathway is involved in the regulation of TDAG51 expression.

\section{TDAG51 protein expression in tumor cells is regulated by MAP kinases}

To investigate whether MAP kinases are also involved in the constitutive expression of TDAG51 in different Ras-mutated tumor cell lines, we supplemented the culture medium with the ERK1/2 inhibitors U0126 and PD98059 and the p38 MAP kinase inhibitor SB203580 either individually or in different combinations repeatedly four times to the cultures, as described in detail in 'Materials and Methods'. As shown in Figure $6 a$ and $b$, the ERK1/2 inhibitors U0126 and PD98059 reduced the constitutive TDAG51 protein expression in all pancreas carcinoma cell lines, whereas the PKC inhibitor Gö6983 at $5 \mu \mathrm{M}$ did not have a significant effect, and SB203580 showed only a weak reduction of TDAG51 expression. In contrast to the inducible TDAG51 expression in T-cells (Figure 4, Table 1), there was no synergistic inhibitory effect when the different MAP kinase inhibitors were combined with Gö6983. In this case, the reduced TDAG51 expression was comparable to that seen when tumor cells were incubated with MAP kinase inhibitors alone (Figure 6a).

\section{Inducible TDAG51 expression in TetOn Jurkat cells does not influence cell proliferation}

As shown above, TDAG51 is constitutively expressed in tumor cells of epithelial origin, and is inducibly expressed in lymphoid cells. To directly investigate the possible effects of TDAG51 expression in T-cells, we used the TetOn system to generate inducible Jurkat lines which were transfected with the empty TRE vector or the TDAG51-containing vector. The induction of TDAG51 by doxycycline (Doxy) in this TetOn Jurkat lines is shown in Figure 7a. As can be seen, TDAG51 
a

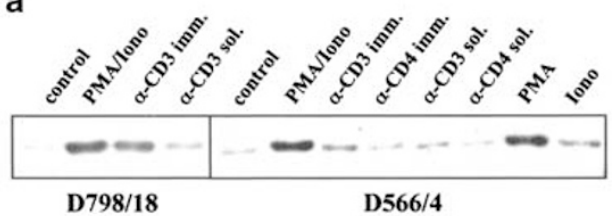

b

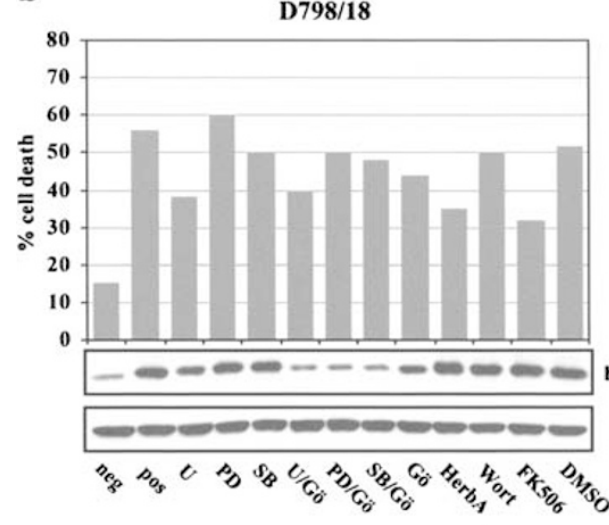

d

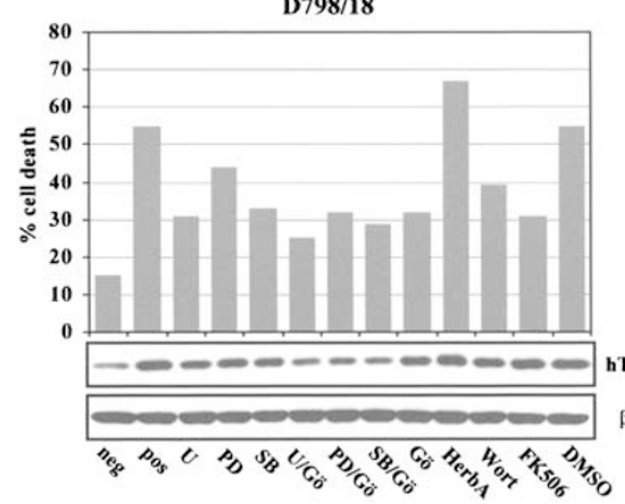

C D596/6

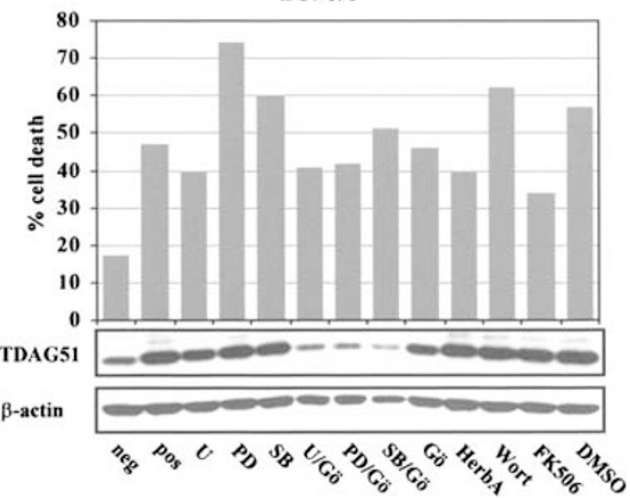

e

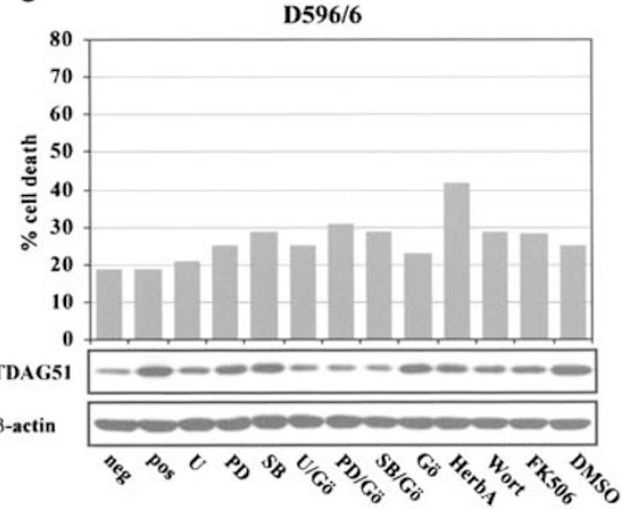

Figure 4 Correlation between TDAG51 protein expression and cell death. T-cell clones D798/18 (AICD-sensitive) and D566/4 (AICD-resistant) were cultured in medium alone (control) or in the presence of PMA, ionomycin, a combination of PMA and ionomycin, immobilized or soluble anti-CD3 or anti-CD4 mAb for $5 \mathrm{~h}$. TDAG51 expression in cell lysates was determined using the polyclonal anti-TDAG51 antibody L-19 (a). T-cell clones D798/18 (b, d) and D596/6 (AICD-resistant; c, e) were stimulated with PMA/ionomycin (b, c) or anti-CD3 mAb OKT3 (d, e). ERK1/2 inhibitors U0126 (U), PD98059 (PD), p38 MAP kinase inhibitor SB203580 (SB) and PKC inhibitor Gö6983 (Gö) alone or in combination, src-kinase inhibitor herbimycin A (HerbA), Pl3-kinase inhibitor wortmannin (Wort) or FK506 were applied $1 \mathrm{~h}$ before stimulation, as described in Materials and Methods. The DMSO solvent control contained 0.5\% DMSO, equivalent to the highest DMSO concentration present in any of the inhibitors. After $5 \mathrm{~h}$, TDAG51 expression in cell lysates was determined using the PHLDA-1 mAb. The membranes were stripped and reprobed with anti- $\beta$-actin mAb to control for the loading and transfer, as described in Materials and Methods. Cell death was measured after $20 \mathrm{~h}$ by flow cytometry analysis of propidium iodide-positive cells. One representative (out of four) experiments is shown

protein was induced by Doxy in TetOn Jurkat cells transfected with the human TDAG51 (TDAG) but not the empty (TRE) vector. TDAG51 protein expression was further increased in Doxy-induced TDAG51 TetOn Jurkats by subsequent stimulation with PMA/ionomycin. The effect of TDAG51 overexpression on proliferation is shown in Figure $7 \mathrm{~b}$. Here we compared empty vector-transfected TetOn Jurkat (TRE) and human TDAG51 vector-transfected TetOn Jurkat without (TDAG) or with Doxy induction (TDAG + Doxy). No significant differences between the three cell lines were observed, whether the cells were cultured in medium alone (Figure $7 \mathrm{~b}$, upper panel) or in the presence of PMA and ionomycin (Figure 7b, lower panel) or anti-CD3 mAb (not shown). PMA/ ionomycin induced growth arrest in all the three cell lines (Figure 7b, lower panel). We also analyzed by flow cytometry the effect of TDAG51 overexpression on the expression of different surface molecules such as CD2, CD3, CD4, TCR $\alpha \beta$, MHC I, CD28, activation markers, molecules of the TNF receptor family, chemokine receptors and adhesion molecules. As summarized in Table 2, there was no significant difference in the expression of all analyzed surface molecules between the parental TetOn Jurkat line as compared to the TetOn TRE line or the TetOn TDAG line with/without Doxy. Moreover, TDAG51 overexpression did not influence the effects of PMA/ionomycin stimulation on cell surface marker expression. Finally, we also analyzed protein tyrosine and 
Table 1 Correlation between cell death and intensity of TDAG51 protein expression

\begin{tabular}{|c|c|c|c|c|c|c|c|c|}
\hline & \multicolumn{4}{|c|}{ Clone D798/18 } & \multicolumn{4}{|c|}{ Clone D596/6 } \\
\hline & \multicolumn{2}{|c|}{ PMA/ionomycin } & \multicolumn{2}{|c|}{ OKT3 } & \multicolumn{2}{|c|}{ PMA/ionomycin } & \multicolumn{2}{|c|}{ OKT3 } \\
\hline & $\%$ Cell death & \% TDAG exp. & $\%$ Cell death & \% TDAG exp. & $\%$ Cell death & \% TDAG exp. & $\%$ Cell death & \% TDAG exp. \\
\hline neg. control & 15 & 2.0 & 15 & 2.6 & 17 & 2.6 & 19 & 3.0 \\
\hline pos control & 56 & 11.1 & 55 & 11.1 & 47 & 10.7 & 19 & 13.1 \\
\hline DMSO & 52 & 11.5 & 55 & 10.2 & 57 & 11.6 & 25 & 13.8 \\
\hline U0126 & 38 & 6.5 & 31 & 6.9 & 40 & 7.9 & 21 & 5.2 \\
\hline PD98059 & 60 & 10.5 & 44 & 9.6 & 74 & 10.9 & 25 & 9.5 \\
\hline SB203580 & 50 & 9.8 & 33 & 8.2 & 60 & 9.2 & 29 & 9.8 \\
\hline U/Gö & 40 & 2.1 & 25 & 4.1 & 41 & 2.2 & 25 & 3.8 \\
\hline PD/Gö & 50 & 2.5 & 32 & 4.9 & 42 & 2.1 & 31 & 3.3 \\
\hline SB/Gö & 48 & 2.5 & 29 & 4.1 & 51 & 1.7 & 29 & 4.0 \\
\hline Gö6983 & 44 & 6.5 & 32 & 8.8 & 46 & 6.9 & 23 & 12.2 \\
\hline Herbimycin & 35 & 12.3 & 67 & 9.9 & 40 & 9.5 & 42 & 8.1 \\
\hline Wortmannin & 50 & 12.3 & 39 & 9.0 & 62 & 11.0 & 29 & 7.1 \\
\hline FK506 & 32 & 11.9 & 31 & 11.6 & 34 & 9.8 & 28 & 7.1 \\
\hline
\end{tabular}

The AICD-sensitive clone D798/18 and the AICD-resistant clone D596/6 were cultured in medium (neg), or were stimulated with PMA/ionomycin or immobilized antiCD3 mAb OKT3, in the absence (pos) or presence of DMSO solvent control or the inhibitors U0126, PD98059, SB203580, Gö6983, herbimycin A, wortmannin, FK506, or combinations as indicated. After $5 \mathrm{~h}$, TDAG51 expression was determined by Western blot analysis. Protein bands were scanned and quantified by the Quantity One software in relation to $\beta$-actin bands. The total amount of TDAG51 protein in all bands of one column was set as $100 \%$, and the relative fraction of TDAG51 protein in each lane was calculated (relative intensity). Cell death was analyzed in parallel by PI staining and flow cytometry after $20 \mathrm{~h}$. Numbers indicate the percentage of dead (i.e. PI-positive) cells.
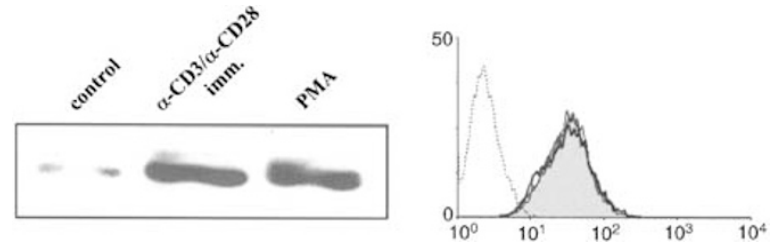

Figure 5 TDAG51 induction and CD95 expression in activated T-cells. PHAblasts were cultured in CM supplemented with rIL-2. On day 20, these preactivated T-cells were stimulated with immobilized anti-CD3 + anti-CD28 mAb or PMA. TDAG51 expression (a) and CD95 expression (b) were determined after $22 \mathrm{~h}$ by Western blot and flow cytometry, respectively. In (b), CD95 expression in $\mathrm{CM}$ alone is shown as a shaded histogram, in the presence of PMA as a bold solid line and after anti-CD3/anti-CD28 crosslinking as a thin solid line. Dotted line: isotype control

ERK1/2 phosphorylation after stimulation with PMA/ionomycin or crosslinking of CD3, but did not detect significant differences upon TDAG51 induction in TetOn Jurkat cells as compared to empty vector transfectants (data not shown).

\section{Discussion}

TDAG51 was originally identified by Park et al. ${ }^{12}$ by differential cDNA library screening of an AICD-sensitive mouse T-cell hybridoma and a mutant that was resistant to AICD mediated via CD3/TCR stimulation, but susceptible to cell death triggered by dexamethasone. Transfection of TDAG51 into the mutant T-cell hybridoma restored anti-CD3 mAb-induced CD95 expression and AICD, suggesting that TDAG51 played an essential role in the induction of apoptosis by coupling TCR stimulation to CD95 expression. This view, however, has been challenged by the observation that T-cells from TDAG51 ${ }^{-/-}$mice do not display discernible defects in CD3/ TCR-dependent upregulation of CD95 expression or AICD. ${ }^{13}$
Since there are several pleckstrin-homology domain-containing proteins with significant homology to TDAG51, ${ }^{18-21}$ it might be possible that one of these homologues fulfills the role ascribed to TDAG51 in normal murine and human T-cells. In line with a dispensable role of TDAG51 in the regulation of AICD, we did not observe a correlation between TDAG51 expression and the induction of AICD in a set of AICDsusceptible and AICD-resistant human T-cell clones. Other reports, however, support a role for TDAG51 in the initiation of cell death. The rat homologue of TDAG51 was thus found to enhance cell death upon microinjection of the corresponding cDNA into a neuronal cell line, and microinjection of an antiTDAG51 antibody increased cell survival. ${ }^{14}$ More recently, TDAG51 was also implied in the regulation of programmed cell death in human vascular endothelial cells triggered by homocysteine. As reported by Hossain et al, ${ }^{22}$ transient overexpression of TDAG51 in vascular endothelial cells elicited changes in cell morphology, decreased cell adherence and promoted apoptosis. Moreover, these authors observed that phosphorylation of the translation initiation factor elF2 $\alpha$ was required for transcriptional activation of TDAG51. ${ }^{22}$ This is of considerable interest, as we have previously identified the p66 subunit of the eukaryotic translation initiation factor elF3 as a binding partner of human TDAG51 in a yeast-two-hybrid screen. ${ }^{23}$ In a luciferase reporter assay, we observed significant inhibition of protein synthesis upon transient cotransfection of TDAG51, suggesting that one role of TDAG51 might be a regulatory impact on protein synthesis. ${ }^{23}$ While the precise function of TDAG51 under physiological and pathophysiological conditions is thus still unclear, the rapidly inducible expression in lymphoid cells together with the constitutive expression in epithelial tumor cells and the reported involvement in cell death control at least in certain cell types, all point to an important role in the regulation of cell growth and differentiation. 
a

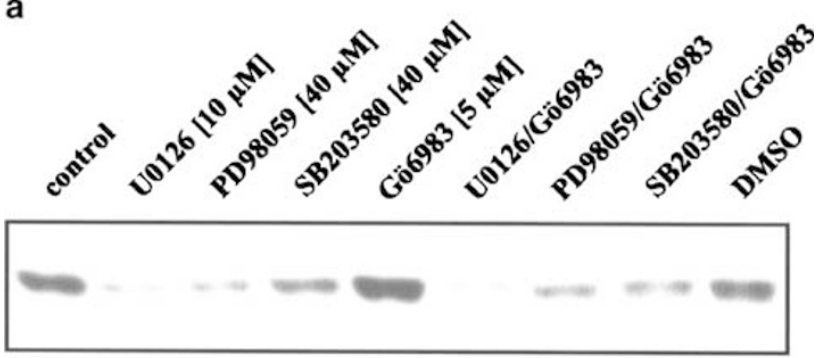

b

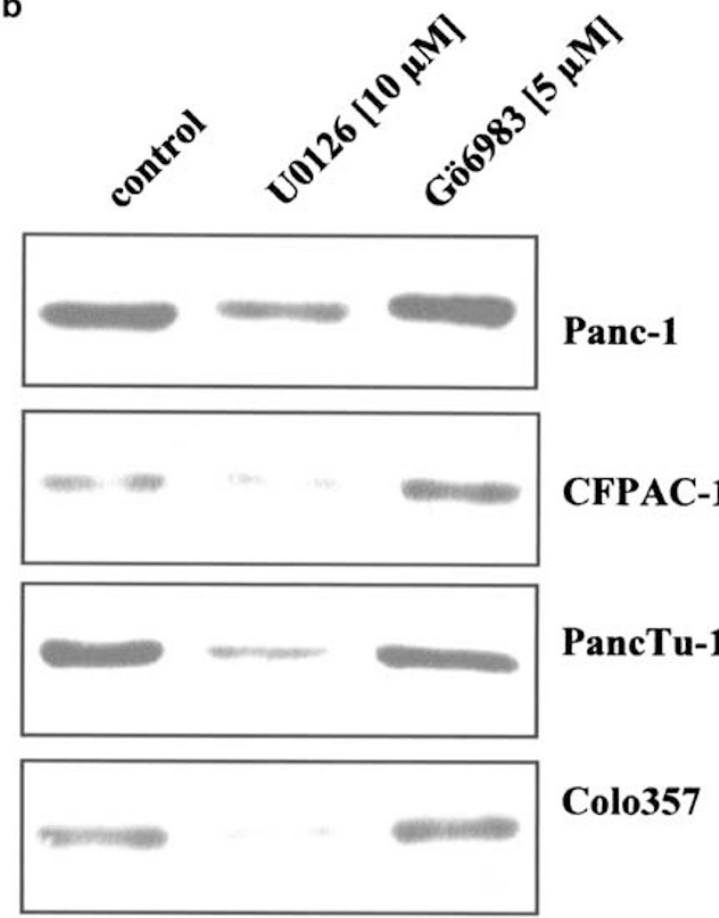

Figure 6 Inhibition of hTDAG51 protein expression in tumor cells. ERK1/2 inhibitors U0126, PD98059, p38 MAP kinase inhibitor SB203580 and PKC inhibitor Gö6983 alone or in combination were applied to cultures of Capan-1 pancreatic tumor cell line, as described in Materials and Methods (a). An additional four tumor cell lines were treated with U0126 or Gö6983 (b). After $40 \mathrm{~h}$, hTDAG51 expression in lysates was determined using the polyclonal antiTDAG51 antibody L-19. This experiment is representative of three experiments

Using well-characterized inhibitors of various signaling pathways, we have compared the inducible expression of TDAG51 in human T-cells with the constitutive expression in pancreatic tumor cells. TDAG51 protein was rapidly induced within $4 \mathrm{~h}$ in resting T-cells by PMA/ionomycin, and was further upregulated within $24 \mathrm{~h}$. While CD3 crosslinking by immobilized anti-CD3mAb alone was less effective, the combined stimulation with anti-CD3 plus anti-CD28 $\mathrm{mAb}$ resulted in efficient TDAG51 induction. The rapid induction of TDAG51 protein correlated well in time with the rapid induction of the activation antigen CD69, which reached almost maximal levels already $4 \mathrm{~h}$ after PMA/ionomycin stimulation (see Figure 2). On the other hand, TDAG51 protein expression clearly preceded the induction of cell surface expression of CD95 and of late activation antigens a
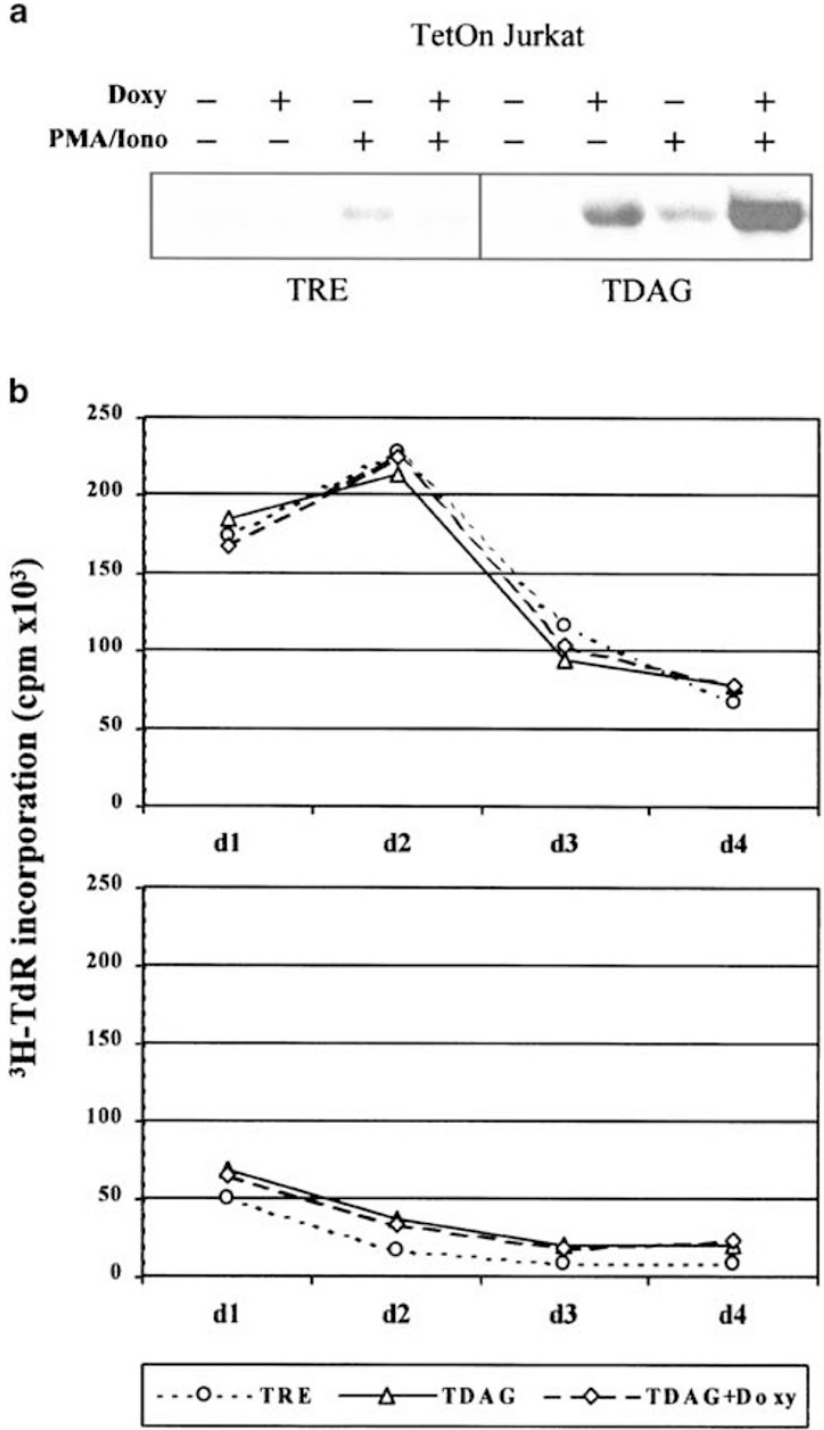

Figure 7 Influence of TDAG51 overexpression on the proliferation of TetOn Jurkat cells. TDAG51 expression in TetOn Jurkat cells transfected with the empty vector (TRE) or with the human TDAG51 vector (TDAG) is shown in (a). Cells were preincubated $(+)$ or not $(-)$ with doxycycline (Doxy) for $24 \mathrm{~h}$, followed by a stimulation or not with a combination of PMA plus ionomycin (PMA/lono) for $5 \mathrm{~h}$. (a) TDAG51 expression in cell lysates was determined using the PHLDA-1 mAb. (b) $5 \times 10^{4}$ TetOn Jurkat cells were seeded in triplicates in 96-well round-bottom tissue culture plates in medium alone (upper part), or stimulated with PMA plus ionomycin (lower part). After 1-4 days, cells were pulsed for $8 \mathrm{~h}$ with ${ }^{3} \mathrm{H}-\mathrm{TdR}$, harvested and analyzed in a $\beta$-counter. One out of three experiments is shown

such as CD25 and HLA-DR. The induction of TDAG51 in human T-cell clones and freshly isolated T-cells was inhibited by MAP kinase inhibitors and by the PKC inhibitor Gö6983, suggesting that both pathways are involved in the induction of TDAG51 in T-cells. A role for PKC in the induction of TDAG51 was previously suggested based on the observation that the known PKC activator PMA alone induced TDAG51 mRNA expression in a murine T-cell hybridoma. ${ }^{16}$ While ERK1/2 inhibitor U0126 alone inhibited TDAG51 induction in T-cells (Figures 3 and 4 , and Table 1), the inhibitory effect was strongly enhanced when PKC was simultaneously inhibited by 
Table 2 Expression of cell surface molecules on TDAG51-overexpressing TetOn Jurkat cells

\begin{tabular}{|c|c|c|c|c|c|c|c|c|}
\hline \multirow[t]{2}{*}{ Antigen } & \multicolumn{2}{|c|}{ pRev } & \multicolumn{2}{|c|}{ TRE } & \multicolumn{2}{|c|}{ TDAG } & \multicolumn{2}{|c|}{ TDAG+Doxy } \\
\hline & Medium & PMA/lono & Medium & PMA/Iono & Medium & PMA/lono & Medium & PMA/lono \\
\hline CD2 & $127^{*}$ & 107 & 178 & 225 & 150 & 221 & 163 & 215 \\
\hline CD3 & 349 & 43 & 352 & 50 & 379 & 48 & 372 & 44 \\
\hline CD4 & 26 & 19 & 9 & 8 & 29 & 20 & 29 & 19 \\
\hline TCR & 26 & 7 & 20 & 7 & 20 & 6 & 21 & 6 \\
\hline $\mathrm{MHC} I$ & 200 & 343 & 158 & 276 & 172 & 349 & 179 & 349 \\
\hline CD28 & 33 & 34 & 302 & 279 & 103 & 93 & 108 & 87 \\
\hline CD25 & 2 & 6 & 2 & 7 & 2 & 11 & 2 & 8 \\
\hline CD45 RA & 6 & 8 & 7 & 10 & 6 & 8 & 6 & 9 \\
\hline CD45 RO & 3 & 4 & 5 & 7 & 3 & 4 & 3 & 4 \\
\hline CD69 & 2 & 368 & 4 & 655 & 2 & 753 & 3 & 652 \\
\hline $\mathrm{MHC}$ II & 2 & 2 & 2 & 2 & 2 & 2 & 2 & 2 \\
\hline TNF-R I & 8 & 4 & 7 & 4 & 5 & 4 & 6 & 5 \\
\hline CD95 & 67 & 63 & 65 & 65 & 60 & 60 & 60 & 61 \\
\hline CD134 & 4 & 4 & 2 & 3 & 2 & 4 & 4 & 4 \\
\hline CXCR3 & 5 & 64 & 5 & 7 & 7 & 5 & 6 & 8 \\
\hline CXCR4 & 111 & 10 & 74 & 34 & 67 & 4 & 62 & 3 \\
\hline CD11a & 3 & 3 & 2 & 2 & 2 & 2 & 2 & 3 \\
\hline CD49f & 11 & 8 & 2 & 2 & 5 & 4 & 5 & 4 \\
\hline
\end{tabular}

pRev TetOn regulatory plasmid-transfected Jurkat line (pRev), empty vector-transfected TetOn Jurkat (TRE) and human TDAG51 vector-transfected TetOn Jurkat without (TDAG) or with doxycycline induction (TDAG+Doxy) were cultured for $5 \mathrm{~h}$ in medium alone or with PMA plus ionomycin (PMA/lono). Thereafter, cells were washed, stained with $\mathrm{mAb}$ directed against the indicated cell surface molecules and analyzed by flow cytometry. Median fluorescence intensity (MFI) was determined with the Cell Quest software (Becton Dickinson). "Figures indicate the median fluorescence intensity (MFI).

Gö6983. A synergistic effect was also observed when Gö6983 was combined with the other MAP kinase inhibitors PD98059 and SB203580, while the latter two were less effective than U0126 when applied alone. Taken together, these results indicate that the efficient induction of TDAG51 expression in human T-cells requires the PKC and the RasRaf-MEK-ERK signaling pathways. We also used the inhibitors to dissect the induction of cell death and expression of CD95 and the regulation of TDAG51 expression in freshly isolated T-cells and T-cell clones, but did not observe a clear correlation. Although the combination of MAP kinase inhibitors and Gö6983 strongly inhibited TDAG51 induction in response to $\mathrm{PMA}$ /ionomycin, they had only marginal effects on subsequent cell death. The combined MAP kinase and PKC inhibitors always suppressed TDAG51 induction following CD3 crosslinking, independently of whether AICD was (clone D798/18; Figure 4D) or was not (clone D596/6; Figure 4E) induced by anti-CD3mAb. Collectively, our experiments with clonally defined human T-cells support the conclusion from studies with TDAG51 ${ }^{-1-}$ mice that - in contrast to the original assumption ${ }^{12}$ - TDAG51 is not involved in the regulation of AICD.

We found that TDAG51 was constitutively expressed at the protein level in a variety of pancreatic tumor cell lines expressing a mutated form of Ras, as well as in several pancreas tumor samples. The constitutive expression of TDAG51 protein in the tumor lines was drastically reduced by ERK1/2 inhibitor U0126, while p38 MAP kinase inhibitor SB203580 was less efficient. Interestingly, no reduction of constitutive TDAG51 protein expression was observed when the tumor cells were cultured in the continuous presence of Gö6983, indicating that - in contrast to the inducible expression in T-cells - PKC is not involved in the constitutive expression of TDAG51 in tumor cells. These results suggest that the mutated Ras might regulate the constitutive TDAG51 expression via the MAP-kinase signaling pathway. In a recent study, Neef et al. ${ }^{15}$ identified human TDAG51 (which they termed PHLDA1 for pleckstrin-homology-like domain family A, member 1 ) by a differential mRNA display between primary and metastatic melanoma cells as a gene that was downregulated in metastatic as compared to primary melanoma. TDAG51 protein was expressed by benign melanocytic nevi, but not in epidermal melanocytes. These authors also established stable TDAG51 transfectants of 293 cells and Mel Rif, a melanoma cell line, and they observed reduced growth rates of the transfectants but no alterations in the expression of a variety of cell surface molecules. Moreover, the stable transfectants displayed slightly increased rates of basal apoptosis, and increased sensitivity to chemotherapeutic drugs. ${ }^{15}$ While these results suggested that TDAG51 is involved in the regulation of cell growth and apoptosis, it is premature to draw definitive conclusions. Thus, despite massive TDAG51 protein expression, some of the presently analyzed pancreatic tumor cells are largely resistant to apoptosis and chemotherapeutic agents. ${ }^{24}$ Moreover, we did not observe any change in the growth pattern of our TetOn Jurkat transfectants upon inducible expression of TDAG51 protein. Despite high-level TDAG51 protein expression, there was no increased sensitivity to apoptosis when compared to non-induced or control vector-transfected TetOn Jurkats.

Although the precise function of TDAG51 remains to be defined, our results provide new insights into the signaling pathways involved in the inducible and constitutive expression in T-lymphocytes and tumor cells, respectively. Since TDAG51 ${ }^{-1-}$ mice do not have obvious abnormalities in the lymphoid compartment and do not suffer from disturbed T-cell apoptosis, ${ }^{13}$ it is possible that certain functions of TDAG51 are 
redundant and can be performed by other, closely related genes. ${ }^{18-21}$

\section{Materials and Methods}

\section{Isolation of T-cells and culture of T-cell clones and tumor cell lines}

Peripheral blood mononuclear cells (PBMC) were isolated by FicollHypaque density gradient centrifugation from buffy coats obtained from healthy blood donors. PBMC were separated into T-cells and non-T-cells by rosetting with neuraminidase-treated sheep erythrocytes and subsequent density gradient centrifugation. Resting T-cells were cultured in complete medium (CM) consisting of RPMI 1640 with 10\% (v/v) FCS (Invitrogen/LifeTechnologies, Karlsruhe, Germany), antibiotics (penicillin at $100 \mathrm{U} / \mathrm{ml}$ and streptomycin at $100 \mu \mathrm{g} / \mathrm{ml})$, L-glutamine $(2 \mathrm{mM})$ and HEPES buffer solution $(25 \mathrm{mM})$ at $37^{\circ} \mathrm{C}$ in a humidified atmosphere with $5 \% \mathrm{CO}_{2}$. The $\mathrm{CD}^{+}$human T-cell clones established from healthy donors have been described, ${ }^{17}$ and were cultured in $\mathrm{CM}$ as described above. Clones were restimulated periodically with irradiated PBMC and EBVtransformed lymphoblastoid cell lines in the presence of PHA $(0.5 \mu \mathrm{g} / \mathrm{ml}$, Murex Biotech Ltd., Dartford, England). At 3-5 days after restimulation, dead cells were removed by centrifugation on Ficoll-Hypaque density gradients. The clone cells were washed and expanded in the presence of $50 \mathrm{U} / \mathrm{ml}$ rlL-2 (sp. Act., $18 \times 10^{6} \mathrm{U} / \mathrm{mg}$, Chiron Behring, Marburg, Germany) for at least 10 days before use in the assay. The pancreatic carcinoma cell lines Panc-1, CFPAC-1, Capan-1, BxPC3, Colo357, PancTu-1, PT45P1 bearing a mutated form of Ras were cultured in CM.

\section{Detection of TDAG51 protein by Western blot analysis}

Cells were pelleted, washed in PBS and lysed in $50 \mu \mathrm{l}$ of Nonidet P40 (Fluka Chemie, Buchs, Switzerland) lysis buffer (1\% (v/v) of detergent in $20 \mathrm{mM}$ Tris- $\mathrm{HCl}(\mathrm{pH} \mathrm{8.1)}, 150 \mathrm{mM} \mathrm{NaCl}$ with protease inhibitors aprotinin, leupeptin, phenyl methyl sulfonyl fluoride, sodium pyrophosphate and sodium fluoride). Lysates remained on ice for 15-30 min before centrifugation at $4^{\circ} \mathrm{C}$ and $14000 \mathrm{rpm}$ for $10 \mathrm{~min}$. The protein content of supernatants was determined by Coomassie Protein Assay Reagent (Pierce, Rockford, IL, U.S.A.) and adjusted to $50-80 \mu \mathrm{g}$ total protein/lane. Samples were boiled in reducing sample buffer with $\beta$-mercaptoethanol, separated on $10 \%$ SDS-polyacrylamide gels, and protein was transferred to nitrocellulose membranes (Hybond C-Extra, Amersham, Braunschweig, Germany). Blots were blocked with 5\% BSA (Sigma-Aldrich, Taufkirchen, Germany) and TDAG51 protein was detected with purified mAb PHLDA$1^{15}$ (a gift from Dr. J Johnson, Munich) or polyclonal Ab L-19 (Santa Cruz, Santa Cruz, CA, USA), followed by HRP-conjugated sheep anti-mouse (Amersham) or bovine anti-goat (Santa Cruz) Ab and chemiluminescence detection reagent (ECL, Amersham). As a control of loading and transfer, membranes were stripped $(62.5 \mathrm{mM}$ Tris- $\mathrm{HCl}$ pH $6.8 ; 100 \mathrm{mM}$ $\beta$-mercaptoethanol, $2 \% \mathrm{SDS}$ ) for $30 \mathrm{~min}$ at $56^{\circ} \mathrm{C}$ and reprobed with anti- $\beta$-actin $\mathrm{mAb}$ (A5441 from Sigma). $\beta$-actin bands were quantified by the Quantity One software (Biorad; Munich) to normalize the TDAG51 protein expression to the overall protein content.

\section{RT-PCR of TDAG51}

TDAG51 mRNA was analyzed using a PCR approach based on total RNA. $3 \times 10^{6}$ cells were incubated in CM in the absence or presence of agents for the time periods detailed in Results section. The cells were then washed in cold PBS and total RNA was isolated using the Qiagen RNeasy $^{\mathrm{TM}}$ Total RNA Kit (Qiagen, Hilden, Germany). The RNA was quantified, and aliquots of $0.5 \mu \mathrm{g} / \mathrm{sample}$ were subjected to RT-PCR using RNA PCR kit from Perkin-Elmer (Roche Molecular Systems, Branchburg, NJ, USA). The following oligonucleotide primers were used: for human TDAG51: sense 5'-ATA-AGG-ATC-CCT-GGA-GAG-TAG-CGG-CTG-C-3' and antisense 5'-ATA-AGA-ATT-CTC-AGG-CAG-AGT-TGG-AGG-T-3' (Eurogentec, Cologne, Germany) to yield the complete 797 bp sequence. PCR was performed with 35 cycles and an annealing temperature of $62^{\circ} \mathrm{C}$ for TDAG51. PCR products were analyzed following separation by electrophoresis in $1 \%$ agarose gel.

\section{Immunohistochemistry}

Normal and ductal pancreatic carcinoma tissues were removed freshly from resection specimens according to the permission of the local ethical committee (permission number 110/99). Samples were snap frozen in a mixture of isopentane and dry ice and stored at $-80^{\circ} \mathrm{C}$. For immunostaining, $5 \mu \mathrm{m}$ cryosections were cut, dried and fixed in acetone for $10 \mathrm{~min}$. Fixed frozen sections were incubated with $0.03 \%$ hydrogenperoxidase for $2 \times 20 \mathrm{~min}$. Intrinsic avidin and biotin were blocked with avidin-biotin-blocking kit from Vector Laboratories (Burlingame, CA, USA). Serum blocking and detection were performed with peroxidasebased mouse Vectastain Kit (Vector Laboratories, Burlingame, CA, USA) according to the instructions. The primary antibody was anti-TDAG51 mAb PHLDA-1 applied at $5 \mu \mathrm{g} / \mathrm{ml}$ concentration. As a negative control, the primary antibody was replaced by mouse IgG1 (DAKO, Hamburg, Germany) in the same concentration.

\section{Flow cytometry}

$5-10 \times 10^{4} \mathrm{~T}$-cells or TetOn Jurkat cells were washed twice with washing buffer (1\% BSA/PBS) and incubated with primary mAb for $20 \mathrm{~min}$ at $4^{\circ} \mathrm{C}$. Thereafter, the cells were washed twice. Unconjugated or biotinylated primary $\mathrm{mAb}$ were detected by second-step reagents, that is, PEconjugated goat $\mathrm{F}\left(\mathrm{ab}^{\prime}\right)_{2}$ anti-mouse $\mathrm{Ab}$ (Caltag, Burlingame, $\mathrm{CA}, \mathrm{USA}$ ) or $\mathrm{PE}$-conjugated streptavidin (Streptavidin-PE; BD Biosciences), respectively. The cells were incubated for $20 \mathrm{~min}$ with second step reagents, washed twice, and fixed in $100 \mu \mathrm{l} 1 \%$ paraformaldehyde/PBS. We used the following mAb as PE-conjugates: CD2, CD3, CD4, CD11a, CD25, CD28, CD45RO, CD69, CD95, HLA-DR (MHC II), TNF-R I (all from BD Biosciences, Heidelberg, Germany) and chemokine receptor mAb CXCR3 (R\&D Systems, Wiesbaden, Germany). The following mAb were used as FITC-conjugates: TCR $\alpha \beta, \mathrm{CD} 11 \mathrm{a}, \mathrm{CD} 45 \mathrm{RA}, \mathrm{CD} 18$ (all from BD Biosciences, Heidelberg, Germany) and w6/32 (MHC I). In addition, we used biotin-conjugated CD134 mAb (BD Biosciences) and unconjugated CXCR4 mAb (R\&D). Appropriate fluorochrome-labeled isotype controls were included. All analyses were measured on a FACScan flow cytometer using the CellQuest software (Becton Dickinson). Results are presented as the median fluorescence intensity (MFI).

\section{Inhibition of TDAG51 expression in T-cells and tumor cells}

The following inhibitors were used: MAP kinase kinase inhibitors U0126 $(10 \mu \mathrm{g} / \mathrm{ml})$, PD98059 $(40 \mu \mathrm{g} / \mathrm{ml})$, p38 MAP kinase inhibitor SB203580 $(40 \mu \mathrm{g} / \mathrm{ml}),{ }^{25-27}$ which block downstream events of the Ras/Raf pathway, PKC inhibitor Gö6983 $(5 \mu \mathrm{g} / \mathrm{ml}),{ }^{28}$ src-kinase inhibitor Herbimycin A $(1.5 \mu \mathrm{M}),{ }^{29}$ PI3-kinase inhibitor Wortmannin $(100 \mathrm{nM})^{30}$ and FK506 
$(10 \mathrm{ng} / \mathrm{ml}),{ }^{31}$ which blocks calcium/calmodulin-dependent kinases. All inhibitors were obtained from Calbiochem (Calbiochem-Novabiochem, Bad Soden, Germany) and were disolved in DMSO. The highest concentration of DMSO used in the experiments per se did not show any effect on cell death or TDAG51 protein expression. The optimal working concentration of each inhibitor was initially determined on Jurkat cells and T-cell clones. $1.5 \times 10^{6}$ T-cells were pretreated for $1 \mathrm{~h}$ with different inhibitors before stimulation with a combination of PMA (10 ng/ml, Sigma) and ionomycin ( $500 \mathrm{ng} / \mathrm{ml}$, Calbiochem), immobilized anti-CD3 mAb OKT3 $(10 \mu \mathrm{g} / \mathrm{ml}$, Orthoclone $)$ in the absence or presence of anti-CD28 mAb ( $5 \mu \mathrm{g} / \mathrm{ml}$, clone CD28.2, BD Biosciences), a combination of staphylococcal enterotoxin A and E (SEA/SEE; $1 \mathrm{ng} / \mathrm{ml}$ each, Serva), or PHA $(1 \mu \mathrm{g} / \mathrm{ml})$. Cells were pelleted, lysed and analyzed after 5,12 or $20 \mathrm{~h}$ of stimulation by Western blotting. Tumor cells were cultured in $\mathrm{CM}$ for $24 \mathrm{~h}$ before inhibitors were added. MAP-kinase inhibitors alone, in combination with Gö6983 or Gö6983 alone, were added 40, 24, 14 and $6 \mathrm{~h}$ before Western blot analysis. To avoid the toxic accumulation of DMSO, the medium was exchanged at each time point and supplemented with the different freshly prepared inhibitors in final concentrations as indicated above. Cells were lysed and blotted as described above.

\section{Cell death analysis}

After culture for $20 \mathrm{~h}$ at $37^{\circ} \mathrm{C}, 100 \mu \mathrm{l}$ of the cell suspension was taken and the percentage of dead cells was determined after staining with propidium iodide (PI; $2 \mu \mathrm{g} / \mathrm{ml}$ ) by flow cytometry with a FACScan (Becton Dickinson, Heidelberg, Germany) using the CellQuest software (Becton Dickinson).

\section{TetOn Jurkat cells}

The TetOn Jurkat cell line was purchased from Clontech (BD Biosciences, Heidelberg, Germany). This cell line is stably transfected with the pRevTetOn regulatory plasmid. We transfected this cell line with the pRevTRE response plasmid or with the human TDAG51 gene containing pRevTRE (pRevTDAG), which was kindly provided by Dr. Thomas Hinz (Paul-Ehrlich-Institut, Langen, Germany). Transfection was performed by electroporation with the Biorad Gene Pulser II and Gene Pulser II RF Module (Biorad, Munich, Germany). Transfected cells were selected and cultured with G418 (1 mg/ml, PAA, Cölbe, Germany) and Hygromycin A (100 $\mu \mathrm{g} / \mathrm{ml}$, Merck, Darmstadt, Germany) in 7.5\% tetracycline approved FBS (Clontech). At $24 \mathrm{~h}$ before the experiments were set up, cells were washed and cultured in $\mathrm{CM}$ without selection.

\section{${ }^{3} \mathrm{H}$-thymidine incorporation}

$5 \times 10^{4}$ TetOn Jurkat cells were seeded in CM in triplicates in 96-well round-bottom culture plates and pulsed for $8 \mathrm{~h}$ with $1 \mu \mathrm{Ci}\left[{ }^{3} \mathrm{H}\right]$ thymidine/ well (Amersham Bioscience) on days 1-4 of culture. The cells were disrupted by freezing and thawing and were harvested using a 96 -well Cell Harvester (Inotech). Filters were counted in the Trace $96 \beta$-counter (Inotech). Results are expressed as the mean cpm of triplicate cultures. Standard deviations were less than $15 \%$.

\section{Acknowledgements}

We gratefully acknowledge Professor Judith Johnson for her generous gift of PHLDA1 monoclonal antibody and Dr. Thomas Hinz for providing the pRevTDAG vector. We thank Maria Niggemeier for expert technical assistance. This work was supported by a grant from the Deutsche Forschungsgemeinschaft (SFB 415 A14 to Dieter Kabelitz).

\section{References}

1. Kabelitz D, Pohl T and Pechhold K (1993) Activation-induced cell death (apoptosis) of mature peripheral T lymphocytes. Immunol. Today 14: 338-339

2. Dhein J, Walczak H, Baeumler C, Debatin KM and Krammer PH (1995) Autocrine T-cell suicide mediated by APO-1/(Fas/CD95). Nature 373: 438-441

3. Brunner T, Mogil RJ, LaFace D, Yoo NJ, Mahboubi A, Echeverri F, Martin SJ, Force WR, Lynch DH, Ware CF and Green DR (1995) Cell-autonomous Fas (CD95)/Fas-ligand interaction mediates activation-induced apoptosis in T-cell hybridomas. Nature 373: 441-444

4. Ju ST, Panka DJ, Cui H, Ettinger R, el-Khatib M, Sherr DH, Stanger BZ and Marshak-Rothstein A (1995) Fas(CD95)/FasL interactions required for programmed cell death after T-cell activation. Nature 373: 444-448

5. Wesselborg S, Janssen $O$ and Kabelitz D (1993) Induction of activation-driven death (apoptosis) in activated but not resting peripheral blood $\mathrm{T}$ cells. J. Immunol. 150: 4338-4345

6. Kirchhoff S, Muller WW, Krueger A, Schmitz I and Krammer PH (2000) TCRmediated up-regulation of C-FLIP ${ }_{\text {short }}$ correlates with resistance toward CD95mediated apoptosis by blocking death-inducing signaling complex activity. J. Immunol. 165: 6293-6300

7. Kirchhoff S, Muller WW, Li-Weber M and Krammer PH (2000) Up-regulation of c-FLIP $P_{\text {short }}$ and reduction of activation-induced cell death in CD28-costimulated human T cells. Eur. J. Immunol. 30: 2765-2774

8. Lens SM, Kataoka T, Fortner KA, Tinel A, Ferrero I, MacDonald RH, Hahne M, Beermann F, Attinger A, Orbea HA, Budd RC and Tschopp J (2002) The caspase 8 inhibitor C-FLIP $P_{L}$ modulates T-cell receptor-induced proliferation but not activation-induced cell death of lymphocytes. Mol. Cell. Biol. 22: 5419-5433

9. Thome M and Tschopp J (2001) Regulation of lymphocyte proliferation and death by FLIP. Nat. Rev. Immunol. 1: 50-58

10. Schmitz I, Krueger A, Baumann S, Schulze-Bergkamen H, Krammer PH and Kirchhoff S (2003) An IL-2-dependent switch between CD95 signaling pathways sensitizes primary human $\mathrm{T}$ cells toward CD95-mediated activation-induced cell death. J. Immunol. 171: 2930-2936

11. Peter ME and Krammer PH (2003) The CD95(APO-1/Fas) DISC and beyond. Cell Death Differ 10: 26-35

12. Park CG, Lee SY, Kandala G, Lee SY and Choi Y (1996) A novel gene product that couples TCR signaling to Fas(CD95) expression in activation-induced cell death. Immunity 4: 583-591

13. Rho J, Gong S, Kim N and Choi Y (2001) TDAG51 is not essential for Fas/ CD95 regulation and apoptosis in vivo. Mol. Cell. Biol. 21: 8365-8370

14. Gomes I, Xiong W, Miki T and Rosner MR (1999) A proline- and glutamine-rich protein promotes apoptosis in neuronal cells. J. Neurochem. 73: 612-622

15. Neef R, Kuske MA, Pröls $E$ and Johnson JP (2002) Identification of the human PHLDA1/TDAG51 gene: down-regulation in metastatic melanoma contributes to apoptosis resistance and growth deregulation. Cancer Res. 62: 5920-5929

16. Wang R, Zhang L, Yin D, Mufson RA and Shi Y (1998) Protein kinase $C$ regulates Fas (CD95/Apo-1) expression. J. Immunol. 161: 2201-2207

17. Oberg HH, Lengl-Janßen B, Kabelitz D and Janssen $O$ (1997) Activationinduced T cell death: resistance or susceptibility correlate with cell surface Fas ligand expression and T helper phenotype. Cell. Immunol. 181: 93-100

18. Qian N, Frank D, O'Keefe D, Dao D, Zhao L, Yuan L, Wang Q, Keating M, Walsh C and Tycko B (1997) The IPL gene on chromosome 11p15.5 is imprinted in humans and mice and is similar to TDAG51, implicated in Fas expression and apoptosis. Hum. Mol. Genet. 6: 2021-2029

19. Hu RJ, Maxwell PL, Connors TD, Johnson LA, Burn TC, Su K, Landes GM and Feinberg AP (1997) A 2.5-Mb transcript map of a tumor-suppressing subchromosomal transferable fragment from 11p15.5, and isolation and sequence analysis of three novel genes. Genomics 46: 9-17

20. Lee MP and Feinberg AP (1998) Genomic imprinting of a human apoptosis homologue, TSSC3. Cancer Res. 58: 1052-1056

21. Frank $D$, Mendelsohn $C L$, Ciccone $E$, Svensson $K$, Ohlsson $R$ and Tycko BA (1999) A novel pleckstrin homology-related gene family defined by Ipl/Tssc3, TDAG51, and Tih1: tissue-specific expression, chromosomal location, and parental imprinting. Mamm. Genome 10: 1150-1159 
22. Hossain GS, van Thienen JV, Werstuck GH, Zhou J, Sood SK, Dickhout JG, de Koning ABL, Tang D, Wu D, Falk E, Poddar R, Jacobsen DW, Zhang $\mathrm{K}$, Kaufman RJ and Austin RC (2003) TDAG51 is induced by homocysteine, promotes detachment-mediated programmed cell death, and contributes to the development of atherosclerosis in hyperhomocysteinemia. J. Biol. Chem. 278: 30317-30327

23. Hinz T, Flindt S, Marx A, Janssen $O$ and Kabelitz D (2001) Inhibition of protein synthesis by the T cell receptor-inducible human TDAG51 gene product. Cell. Signal. 13: 345-352

24. Ungefroren $H$, Voss M, Jansen M, Roeder C, Henne-Bruns D, Kremer B and Kalthoff $\mathrm{H}$ (1998) Human pancreatic adenocarcinomas express Fas and Fas Ligand yet are resistant to Fas-mediated apoptosis. Cancer Res. 58: 1741-1749

25. Favata MF, Horiuchi KY, Manos EL, Daulerio AJ, Stradley DA, Feeser WS, van Dyk DE, Pitts WJ, Earl RA, Hobbs F, Copeland RA, Magolda RL, Scherle PA and Trzaskos JM (1998) Identification of a novel inhibitor of mitogen-activated protein kinase kinase. J. Biol. Chem. 273: 18623-18632

26. Dudley DT, Pang L, Decker SJ, Bridges AJ and Saltiel AR (1995) A synthetic inhibitor of the mitogen-activated protein kinase cascade. Proc. Natl. Acad. Sci. USA 92: $7686-7689$
27. Davies SP, Reddy H, Caivano M and Cohen P (2000) Specificity and mechanism of action of some commonly used protein kinase inhibitors. Biochem. J. 351: 95-105

28. Stempka L, Girod A, Müller HJ, Rincke G, Marks F, Gschwendt M and Bossemeyer D (1997) Phosphorylation of protein kinase C (PKC) at threonine 505 is not a prerequisite for enzymatic activity. Expression of rat PKC and an alanine 505 mutant in bacteria in a functional form. J. Biol. Chem. 272: $6805-6811$

29. Uehara $Y$, Fukazawa $H$, Murakami $Y$ and Mizuno $S$ (1989) Irreversible inhibition of $\mathrm{v}$-src tyrosine kinase activity by herbimycin $\mathrm{A}$ and its abrogation by sulfhydryl compounds. Biochem. Biophys. Res. Commun. 163: 803-809

30. Powis G, Bonjouklian MM, Berggren A, Gallegos R, Abraham C, Ashendel A, Zalkow W, Matter WF, Dodge J, Gridey G and Vlahos CJ (1994) Wortmannin, a potent and selective inhibitor of phosphatidylinositol-3-kinase. Cancer Res. 54: 2419-2423

31. Sawada S, Suzuki G, Kawase Y and Takaku F (1987) Novel immunosuppressive agent, FK506. In vitro effects on the cloned T cell activation. J. Immunol. 139: 1797-1803 